\title{
Effects of humidity and other factors on the generation and sampling of a coronavirus aerosol
}

\author{
Seung Won Kim • M. A. Ramakrishnan • \\ Peter C. Raynor · Sagar M. Goyal
}

Received: 27 April 2007 / Accepted: 20 June 2007/Published online: 25 July 2007

(C) Springer Science+Business Media B.V. 2007

\begin{abstract}
Suspensions of transmissible gastroenteritis virus (TGEV), a porcine coronavirus, were nebulized at rates of $0.1-0.2 \mathrm{ml} / \mathrm{min}$ into moving air using a Collison nebulizer or a plastic medical nebulizer operating at pressures ranging from 7 to $15 \mathrm{psi}$. The airborne viruses were collected on heating, ventilating, and air conditioning (HVAC) filters in an experimental apparatus and also sampled upstream of these test filters using AGI-30 and BioSampler impinger samplers. To study the effects of relative humidity $(\mathrm{RH})$ on TGEV collection by the filters and samplers, the virus was nebulized into air at $30,50,70$, and $90 \% \mathrm{RH}$. There were no significant changes in virus titer in the nebulizer suspension before and after nebulization for either nebulizer at any of the pressures utilized. Aerosolization efficiency - the ratio of viable virus sampled with impingers to the quantity of viable virus nebulized decreased with increasing humidity. BioSamplers detected more airborne virus than AGI-30 samplers at all RH levels. This difference was statistically
\end{abstract}

S. W. Kim · P. C. Raynor ( $₫)$

Division of Environmental Health Sciences, School of Public Health, University of Minnesota, Mayo MC 807, 420 Delaware St. S.E., Minneapolis, MN 55455, USA e-mail: praynor@umn.edu

M. A. Ramakrishnan · S. M. Goyal Department of Veterinary Population Medicine, College of Veterinary Medicine, University of Minnesota, 1333 Gortner Ave., St. Paul, MN 55108, USA significant at 30 and 50\% RH. Nebulizer type and pressure did not significantly affect the viability of the airborne virus. Virus recovery from test filters relative to the concentration of virus in the nebulizer suspension was less than $10 \%$. The most and the least virus were recovered from filter media at $30 \%$ and $90 \% \mathrm{RH}$, respectively. The results suggest that TGEV, and perhaps other coronaviruses, remain viable longer in an airborne state and are sampled more effectively at low RH than at high humidity.

Keywords Bioaerosol - Coronavirus · Humidity · Nebulizer · Sampling $\cdot$ TGEV $\cdot$ Virus
Abbreviations
AGI All-glass impinger
CPE Cytopathic effects
HEPA High-efficiency particulate air
HVAC Heating, ventilating, and air conditioning
MEM Minimum essential medium
MERV Minimum efficiency reporting value
SARS Severe acute respiratory syndrome
ST Swine testicular
$\mathrm{TCID}_{50} \quad 50 \%$ tissue culture-infecting dose
TGEV Transmissible gastroenteritis virus

\section{Introduction}

Viruses are an important class of microorganisms that can pose serious airborne hazards to clinical and 
non-clinical health care workers and workers handling animals. Potential threats to the general public include bioterrorism, especially from the smallpox virus, and emerging infectious diseases, such as severe acute respiratory syndrome (SARS) and avian influenza. Thus, virtually everyone is at the risk of exposure to contagious viruses via inhalation.

Viruses differ from other microorganisms in that they can replicate only inside a host cell. However, they can survive in the environment and be transmitted through air in the absence of host cells (Gerone et al. 1966). Viruses are 20-300 nm in size, and they usually travel in air carried by other materials, such as droplets of respiratory secretions or dust particles (Otten and Burge 1999). Epidemiological evidence suggests that the transmission of viral infections may occur inside and between neighboring buildings (Donaldson 1978; Riley et al. 1978). Blood and tissue aerosols generated during general and dental surgery may also contribute to the transmission of these viruses (Reponen et al. 2001).

Testing the ability of heating, ventilating, and air conditioning (HVAC), respiratory protection, and other filters to capture biological aerosols is important to ensure that the filters perform as expected. Viruses are more difficult and expensive to use as a test aerosol for filters than other biological particles, and considerable background knowledge and experience are required to handle them properly. Particles the size of single viruses will be captured primarily by Brownian diffusion (Lee and Liu 1982). However, few studies have measured the collection efficiency of filters challenged by virus particles. Although bacteriophages (e.g., MS2) have been used as a surrogate for human viruses in some studies (Foarde et al. 1999; Research Triangle Institute 2004), they cannot be expected to represent all types of human and animal viruses. Hence, studies with these viruses are sorely needed.

In this study, we used transmissible gastroenteritis virus (TGEV) of pigs as a surrogate for SARS virus. Laboratory studies using TGEV are safe to perform because the virus has no known adverse effect on humans. Further, the data obtained using TGEV should be applicable to the SARS virus because both TGEV and SARS virus are enveloped, positive-stranded RNA viruses belonging to the family Coronaviridae (Fauquet et al. 2005) and their physicochemical properties are similar. Although TGEV has been utilized previously as a SARS virus surrogate for studies of their genome expression (Thiel et al. 2003), it has not been used in studies investigating the sampling and behavior of viral aerosols (Spendlove and Fannin 1982; Tseng and Li 2005).

The methodology for generating, storing, and collecting viral aerosols has been reviewed by a number of authors(Sattar and Ijaz 1987; Cox 1989; Mitchell 1995; Buttner et al. 2002; Sattar and Ijaz 2002). Factors affecting the viability of a virus during nebulization include nebulizer type, nebulizer air pressure, nebulization time, microorganism type, and humidity of the dilution air (Adams et al. 1982; Sattar and Ijaz 1987). Marthi (1994) listed humidity, temperature, radiation, and open-air factors (Cox et al. 1973) as the most important parameters influencing the viability of airborne microorganisms. The method of aerosol generation, composition of the generation fluid, sampling method, and collection medium were deemed to be secondary parameters. Although some factors may be more important than others for a particular virus, all of them play a role in viral aerosol viability (Spendlove and Fannin 1982).

Humidity in buildings can vary as a function of season and location; consequently, it is an important factor to study in terms of virus viability in the indoor environment. Bacteriophages, influenza viruses, and reoviruses each exhibit a unique dependence on relative humidity (RH) (Loosli et al. 1943; Hemmes et al. 1962; Adams et al. 1982; Trouwborst and De Jong 1973). However, the influence of humidity on the viability of coronaviruses such as the SARS virus and TGEV has not been studied previously.

All-glass impingers (AGI) are commonly used for collecting viral aerosols (Spendlove and Fannin 1982; Sattar and Ijaz 1987; Sattar and Ijaz 2002; Tseng and Li 2005). BioSamplers were developed by Willeke et al. (1998), and their sampling performance for bacteria and fungi has been studied (Lin et al. 1999, 2000). AGI-30 samplers collect most particles larger than $0.3 \mu \mathrm{m}$ in diameter (Buttner and Stetzenbach 1991). The physical collection efficiency of the BioSampler has been shown to be about $79,89,96$, and $100 \%$ for $0.3-, 0.5-, 1-$, and 2- $\mu \mathrm{m}$ particles, respectively (Willeke et al. 1998). BioSamplers yield equivalent or higher culturable counts of bacteria relative to AGI-30 samplers under the same conditions (Lin et al. 1999). The physical sampling efficiency for both the AGI-30 and the BioSampler is less than $50 \%$ for particles with a diameter of less than $0.3 \mu \mathrm{m}$ and less than $10 \%$ for many particles with a diameter smaller than $0.1 \mu \mathrm{m}$ 
(Hogan et al. 2005). These authors also showed that the recovery of airborne MS2 and T3 bacteriophages using an AGI-30 sampler was greater than that using a BioSampler. However, comparisons of BioSampler and AGI-30 performance have not been made for coronaviruses such as SARS virus and TGEV.

The ability of samplers to collect airborne particles with submicrometer diameters is important because many particles produced by coughing and sneezing are less than a micrometer in diameter. Gerone et al. (1966) found that $50 \%$ of the particles produced by sneezing and $73 \%$ of the particles produced by coughing were smaller than $1 \mu \mathrm{m}$ in diameter. Nicas et al. (2005) correctly pointed out that most of the mass of particles produced by coughing and sneezing will initially be in particles larger than $1 \mu \mathrm{m}$ in diameter. However, the water portion of droplets smaller than about $25 \mu \mathrm{m}$ in diameter will evaporate almost instantaneously leaving much smaller virus-containing particles suspended in the air (Musher 2003).

Filtration is an important method for reducing concentrations of biological particles inside of buildings. The possibility of using HVAC filters as a sampling system for airborne microorganisms has recently been proposed (Farnsworth et al. 2006). In addition, due to the threats of bioterrorism and pandemic influenza, more consideration is being given to the virus removal efficiency of filters in HVAC systems (Hitchcock et al. 2006).

The objective of this study was to characterize factors affecting TGEV nebulization and to select the best sampling procedure for measuring the airborne concentration of this coronavirus. Characterization of factors affecting virus nebulization can be an important step towards the use of viruses as test aerosols. Once we are able to produce reliable virus-containing aerosols, that knowledge can be used in many ways; for example, respirator and ventilation filters can be tested for their virus filtration efficiencies, and virologists and toxicologists can use these techniques in their health effects research.

\section{Materials and methods}

\subsection{Experimental design}

Measurements of airborne TGEV concentrations and the recovery of TGEV from a filter medium were performed using an air filter testing apparatus. Suspensions of TGEV were placed in a nebulizer and aerosolized into air flowing through the apparatus. The TGEV suspensions were titrated before and after nebulization on 36 different occasions to evaluate the effects of nebulization on virus viability. The airborne virus particles were sampled at an $\mathrm{RH}$ of $30,50,70$, and $90 \%$ using two different types of impinger samplers. The virus particles were also collected on filter media inserted into the apparatus. The TGEV collected by the samplers and the TGEV eluted from the test filters were quantified. Each combination of the four humidity levels with the two samplers was repeated three times for a total of 24 separate tests. Using these data, we evaluated the TGEV's airborne concentration and its recovery from test filters as a function of RH and sampler type. Each of the steps in this process is described in more detail in the following sections.

\subsection{Filter test apparatus}

Nebulization experiments were performed in a filter test apparatus (Fig. 1). This apparatus was used by McCullough et al. (1998) to study the penetration and loading of respirator filters with airborne fungi and bacteria. TGEV was aerosolized into the apparatus using a nebulizer and passed through a custom-made charge neutralizer containing a polonium-210 alpha particle source to imbue the virus with an equilibrium charge distribution. This viral aerosol was then mixed thoroughly with filtered dilution air before it entered the test section. The RH of the dilution air was controlled to $30,50,70$, or $90 \%$ ( $\pm 5 \%$ variation). The test section consisted of a $15-\mathrm{cm}$-diameter vertical duct and a pneumatically controlled filter holder. The total air flow rate in this section was $921 / \mathrm{min}$. The temperature during the experiments was approximately $23^{\circ} \mathrm{C}$.

\subsection{Virus preparation}

Swine testicular (ST) cells (ATCC CRL1746) were used for the propagation of the test virus. The cells were grown in Eagle's minimum essential medium (MEM) (Mediatech, Herndon, Va.) containing $150 \mathrm{IU} / \mathrm{ml}$ penicillin, $150 \mu \mathrm{g} / \mathrm{ml}$ streptomycin, $50 \mu \mathrm{g} / \mathrm{ml}$ neomycin, $1 \mu \mathrm{g} / \mathrm{ml}$ fungizone, and $8 \%$ fetal calf serum. The Purdue strain of TGEV was 
Fig. 1 Schematic diagram of the filter test apparatus. HEPA, high-efficiency particulate air

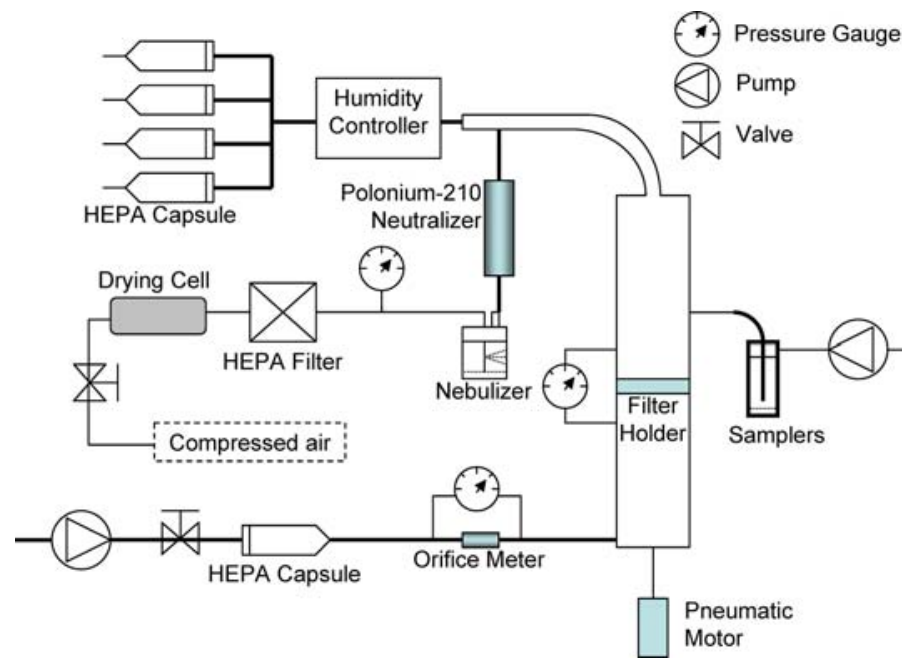

propagated by infecting ST cells grown to $80-90 \%$ confluency. The virus was allowed to adsorb to cells at $37^{\circ} \mathrm{C}$ for $1 \mathrm{~h}$, followed by the addition of MEM without fetal calf serum and incubation at $37^{\circ} \mathrm{C}$. After the appearance of virus-induced cytopathic effects (CPE), generally $48-72 \mathrm{~h}$ post-infection, the cells were subjected to two cycles of freezing and thawing. The cell debris was removed by centrifugation at $4000 \mathrm{~g}$ for $20 \mathrm{~min}$, and the viral supernatant was aliquoted in small vials followed by storage at $-70^{\circ} \mathrm{C}$ until use. On the day of testing, $50 \mathrm{ml}$ of stock virus was thawed at ambient temperature and placed into a nebulizer. The TGEV concentration in the 50-ml suspensions used during the experiments ranged from $1.78 \times 10^{3}$ to $5.62 \times 10^{6} \mathrm{TCID}_{50} / \mathrm{ml} \quad(50 \%$ tissue culture infecting dose per milliliter) with a geometric mean of $8.51 \times 10^{4} \mathrm{TCID}_{50} / \mathrm{ml}$. The TGEV titers utilized in this study were maximized to the best of our ability..2

\subsection{Virus titration}

To determine the titers of TGEV, serial tenfold dilutions of the nebulizer suspensions, the collection liquid from the samplers, and the filter eluates were prepared in maintenance medium, followed by inoculation in ST cells grown in 96-well plates using four wells per dilution. After 4 days of incubation at $37^{\circ} \mathrm{C}$, inoculated cells were examined microscopically for the appearance of virus-specific CPE, and titers were calculated by the Karber method (Karber 1931).

\subsection{Nebulizers and nebulization tests}

To determine the effect of nebulization parameters such as nebulizer type, nebulization time, and incoming air pressure on the virus, the titers of TGEV before and after nebulization were measured. Two nebulizers, a 6-jet Collison nebulizer (BGI, Waltham, Mass.) and a plastic medical nebulizer (Retec Aerosol Generator; Cavitron Corporation, Englewood Cliffs, N.J.), were utilized in initial tests. In subsequent tests, only the Collison nebulizer was used. Dry, filtered air was supplied to the nebulizers at pressures ranging from 7 to 15 psi. For tests during which impinger sampling and collection by filters were performed, air pressure to the Collison nebulizer was fixed at 10 psi. The liquid aerosolization rates for virus suspensions were between 0.1 and $0.2 \mathrm{ml} / \mathrm{min}$ depending on the type of nebulizer and the pressure.

\subsection{Airborne virus sampling}

Airborne virus concentrations were determined using AGIs (AGI-30; Ace Glass, Vineland, N.J.) and BioSamplers (SKC, Eighty Four, Pa.) attached to sampling inlets inserted into the test apparatus. The inlets, with an inside diameter of $0.95 \mathrm{~cm}$, were positioned about $50 \mathrm{~cm}$ upstream from the mounting location of test filters. Although the inlets were perpendicular to the flow direction, losses during sampling were minimal because the flow inside the apparatus was slow enough that a representative sample could be drawn (Brockmann 2001). The flow 
rate for both samplers was $12.5 \mathrm{l} / \mathrm{min}$, and sampling time was limited to $10 \mathrm{~min}$ to minimize both possible stress on viruses and evaporation of the maintenance medium used as the collection liquid. No corrections were applied to account for incomplete physical collection of the airborne viruses or for possible inactivation of TGEV during the sampling procedure.

\subsection{Virus recovery from filters}

To examine the recovery of TGEV from a filter, we selected an HVAC filter medium. These filters (RigaFlo 200PH; Camfil Farr, Rancho Dominguez, Calif) were made from a microfine fiberglass laminated to a reinforcing backing. According to the manufacturer's specifications, this class of filter is rated MERV 14 by the American Society of Heating, Refrigerating and Air-Conditioning Engineers (ASHRAE) Standard 52.2-1999 (ASHRAE 2000). MERV 14 filters have been measured in laboratory tests to have efficiencies of 75-85\% for particles with diameters of $0.3-1.0 \mu \mathrm{m}$ and $90 \%$ or greater for particles with diameters of $1.0-10 \mu \mathrm{m}$. Virus-laden particles with a diameter smaller than $0.3 \mu \mathrm{m}$ would be expected to be collected with at least $75 \%$ efficiency by diffusion. Test filter samples were cut from a regular-pleated HVAC filter media and placed into a plastic holder that was sandwiched between gasketed flanges using the pneumatically controlled mounting system. The portion of the test filters exposed to the TGEV aerosol was a circle (diameter: $14 \mathrm{~cm}$ ), leading to a face velocity at the filter of $10 \mathrm{~cm} / \mathrm{s}$. During each of the 24 separate tests, a filter was exposed to virusladen air for $10 \mathrm{~min}$. Immediately after nebulization, the filter was removed and cut into small pieces that were eluted with $50 \mathrm{ml} 3 \%$ beef extract- $0.05 \mathrm{M}$ glycine solution $(\mathrm{pH}$ 8.8) using a vortex mixer for $1 \mathrm{~min}$. The $\mathrm{pH}$ of the eluate was immediately adjusted to $\mathrm{pH} 7.5$ with $1 \mathrm{M}$ hydrochloric acid.

\subsection{Data analysis}

To assess the effect of nebulization time, the titers of TGEV in the nebulizer suspensions after 10 or 30 min were compared with those of the original suspensions. These times were long enough for $50 \mathrm{ml}$ of a suspension to be circulated through the nebulizer many times. Therefore, we can assume that almost all of the virus in the nebulizer experienced the stress of nebulization at least once. To compare titers before and after nebulization, the quantity $\gamma$ is defined here as

$\gamma=\frac{\mathrm{C}_{\mathrm{a}}}{\mathrm{C}_{\mathrm{b}}}$

where $C_{a}$ is the virus titer after nebulization and $C_{b}$ is the titer before nebulization. For $10 \mathrm{~min}$ of sampling, 24 pairs of virus titers were compared, all using the Collison nebulizer. For 30 min of sampling, 12 pairs of virus titers were compared. Four pairs were from the Collison nebulizer and eight were from the plastic medical nebulizer. Geometric means and $95 \%$ confidence intervals for $\gamma$ were calculated from these data.

To measure the degree to which the nebulizers generated airborne viruses that could be sampled and remain viable, aerosolization efficiency, $\eta_{\mathrm{A}}$, was calculated in the same way as Adams et al. (1982):

$\eta_{\mathrm{A}}=\frac{\mathrm{N}_{\mathrm{a}}}{\mathrm{N}_{\mathrm{n}}} \times 100 \%$

in which $\mathrm{N}_{\mathrm{a}}$ is the total number of viruses recovered from airborne sampling and $N_{n}$ is the total number of viruses aerosolized from the nebulizer during a test. Aerosolization efficiencies smaller than $100 \%$ could be caused by inactivation of the TGEV during transport through the air stream, inactivation due to sampling stresses, and incomplete physical sampling of the test virus. The mean and standard deviation of $\eta_{\mathrm{A}}$ was calculated from the three replicates for each combination of RH and sampler.

The recovery of TGEV from the test filter can be calculated in two ways: (1) relative to the airborne virus concentration, $R_{a}$, and (2) relative to the nebulizer suspension concentration, $R_{n}$. The terms $\mathrm{R}_{\mathrm{a}}$ and $\mathrm{R}_{\mathrm{n}}$ can be calculated according to

$\mathrm{R}_{\mathrm{a}}=\frac{\mathrm{N}_{\mathrm{f}}}{\mathrm{N}_{\mathrm{a}}} \times 100 \%$

$\mathrm{R}_{\mathrm{n}}=\frac{\mathrm{N}_{\mathrm{f}}}{\mathrm{N}_{\mathrm{n}}} \times 100 \%=\frac{\mathrm{N}_{\mathrm{f}}}{\left(\mathrm{V}_{\mathrm{b}}-\mathrm{V}_{\mathrm{a}}\right)\left(\mathrm{C}_{\mathrm{a}}+\mathrm{C}_{\mathrm{b}}\right) / 2} \times 100 \%$

in which $\mathrm{N}_{\mathrm{f}}$ is the total number of viruses recovered from filter, $V_{b}$ is the volume of nebulizer suspension before nebulization, and $\mathrm{V}_{\mathrm{a}}$ is the volume of 
nebulizer suspension after nebulization. The amount of virus aerosolized from the nebulizer was the product of the volume of the nebulizer suspension consumed and the virus titer of the suspension. Each combination of humidity and sampler had three replicates; a mean and a standard deviation for $\mathrm{R}_{\mathrm{a}}$ were calculated for replicates with non-zero virus titers in the collection liquid of the sampler. The mean and standard deviation for $\mathrm{R}_{\mathrm{n}}$ was determined for the six replicates at each $\mathrm{RH}$. Tseng and Li (2005) suggested that $R_{n}$ is a better indicator for virus study than $\mathrm{R}_{\mathrm{a}}$.

\section{Results and discussion}

\subsection{Nebulization tests}

The titers of virus before and after nebulization and values of $\gamma$ calculated from Eq. 1 are summarized in Table 1 for the 36 separate tests. A $\gamma$ of 1 means that the titer is the same after nebulization as before. The $95 \%$ confidence intervals in the table show that the geometric mean of $\gamma$ was not significantly different from 1 for any of the pressures tested; nebulization did not affect the titers significantly. Although the value of $\gamma$ decreased from 1.11 at 7 psi to 0.86 at $15 \mathrm{psi}$, changes in $\gamma$ with pressure were not significant $(P=0.57)$. The effects of nebulizer type and nebulization duration are confounded with pressure. Nonetheless, there were no obvious effects due to these parameters $(P=0.80$ for nebulizer type; $P=0.87$ for nebulization time).

The data indicate that neither the type of nebulizer, the nebulizer pressure, nor the nebulization time was an important factor affecting survival of TGEV during nebulization. Ijaz et al. (1987) found similar results after a 10-min nebulization of human coronaviruses, poliovirus type 1 , rotavirus, and rhinovirus. These findings may be explained by the small size of viruses. Because they are small, they have little inertia when moving, and therefore do not experience much physical stress due to acceleration or deceleration and impaction during nebulization. Viruses with structures differing from those of TGEV may show a different result.

\subsection{Airborne virus sampling}

As shown in Fig. 2, aerosolization efficiency, calculated using Eq. 2, decreased as a function of RH. 


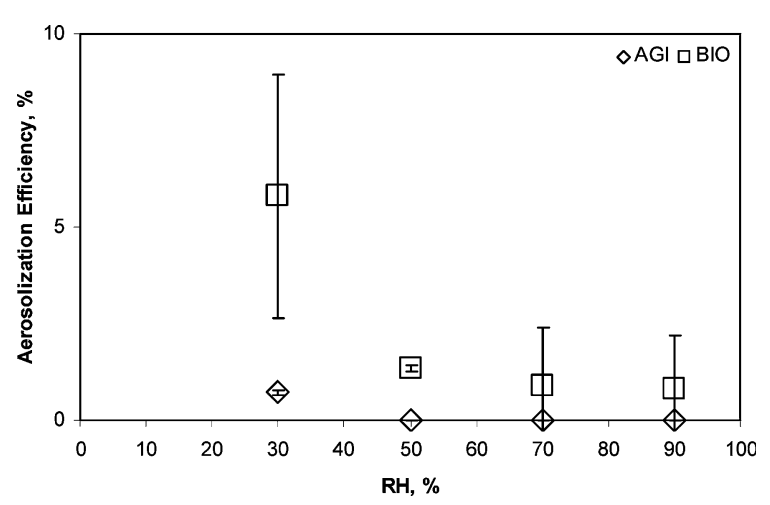

Fig. 2 Aerosolization efficiency, $\eta_{\mathrm{A}}$ from Eq. 2, as a function of relative humidity $(R H)$ measured using the AGI-30 all-glass impinger $(A G I)$ and the BioSampler $(B I O)$. Error bars represent $\pm 1 \mathrm{SD}$ from the mean for each condition

Sampling with BioSamplers led to higher aerosolization efficiency than sampling with AGI-30 samplers. At 30 and $50 \% \mathrm{RH}$, the difference was statistically significant at $P=0.049$ and $P<0.001$, respectively. This suggests that, relative to AGI-30 samplers, BioSamplers may have a higher physical sampling efficiency for the TGEV-containing particles and/or sample in a way that reduces inactivation of TGEV.

Our finding of higher virus levels measured with the BioSampler for the coronavirus TGEV is, in general, opposite the results reported by Hogan et al. (2005) showing higher airborne concentrations measured using the AGI-30 for MS2 and T3 bacteriophages. However, our aerosolization efficiency was similar to those of reoviruses nebulized using a Chicago atomizer without prehumidification of secondary air (Adams et al. 1982). These authors also found that aerosolization efficiencies increased by approximately tenfold following the prehumidifying of the secondary air in the Chicago atomizer.

Two important processes may affect the measurements of aerosolization efficiency in our study: (1) the viruses may have been damaged during sampling and (2) some of them may have passed through the sampler without being collected. These processes were disregarded in the calculations, which would lead to underestimation of true aerosolization efficiencies.

Agranovski et al. (2005) developed and tested a bubbler for sampling airborne microorganisms and utilized it to sample vaccinia virus in laboratory studies with a recovery of about $90 \%$ over $6 \mathrm{~h}$ of sampling. The authors were careful to note that vaccinia strains are more robust than many other viruses. When Agranovski et al. (2004) utilized the bubbler to sample SARS virus experimentally, they recovered more than $10 \%$ of the virus in $2 \mathrm{~h}$ of sampling. A comparison of these data to the results from our study with TGEV suggests that the bubbler may be a more suitable sampler for coronaviruses than the AGI-30 and the BioSampler.

\subsection{Virus recovery from filters}

The two different recoveries calculated by Eqs. 3 and 4 are summarized in Table 2. Because some of the measured airborne virus concentrations were zero, corresponding filter recoveries based on airborne virus concentration, $R_{a}$, could not be calculated. $R_{a}$ estimated using AGI-30 samplers showed higher values than $R_{a}$ from BioSamplers. This could be explained if the sampling efficiency for AGI-30 samplers were lower than that of the BioSampler Some $\mathrm{R}_{\mathrm{a}}$ showed more than $100 \%$ recovery. Loss of survivability or infectivity during sampling could be the reason for these observations. Both $R_{a}$ and $R_{n}$ showed large variations.

Table 2 shows that no virus was found in the three AGI-30 samples at 50, 70, or $90 \% \mathrm{RH}$. For the BioSampler, virus was observed in only one of three samples at 70 and $90 \%$ RH. These results indicate that the sampling of viable airborne TGEV became more difficult as the RH increased and that the BioSampler sampled TGEV somewhat more effectively than the AGI-30.

Virus recovery according to Eq. 3 could not be evaluated for all conditions due to the inability of the samplers to yield sufficient viable TGEV for quantification. If it were possible, higher titers in the nebulizer suspension might have yielded quantifiable concentrations of TGEV in the samplers. However, our methods were optimized to produce titers that were as high as possible for TGEV propagated in ST cells. The inability to quantify TGEV in the samples may be caused primarily by inactivation during travel through the air and during sampling. In addition, the recovery calculated in Eq. 3 may also be inaccurate because the size-selective sampling efficiency of AGI-30 samplers and BioSamplers is low for particles the size of individual viruses (Hogan et al. 2005) 
Table 2 Recovery of virus from the test filters calculated using both Eqs. 3 and 4 as a function of relative humidity and type of sampler

\begin{tabular}{|c|c|c|c|c|c|c|}
\hline \multirow[t]{2}{*}{ RH (\%) } & \multicolumn{4}{|c|}{$\begin{array}{l}\text { Recovery based on impinger samples } \\
\left(\mathrm{R}_{\mathrm{a}} \text { from Eq. } 3\right)\end{array}$} & \multicolumn{2}{|c|}{$\begin{array}{l}\text { Recovery based on nebulizer } \\
\left(R_{n} \text { from Eq. } 4\right)\end{array}$} \\
\hline & Sampler & Number of tests & $\begin{array}{l}\text { Number of tests with virus recovered } \\
\text { from sampler }\end{array}$ & $\mathrm{R}_{\mathrm{a}}$, mean $\pm \mathrm{SD}, \%$ & $\begin{array}{l}\text { Number } \\
\text { of tests }\end{array}$ & $\mathrm{R}_{\mathrm{n}}$, mean $\pm \mathrm{SD}, \%$ \\
\hline \multirow[t]{2}{*}{30} & AGI-30 & 3 & 3 & $556.21 \pm 610.01$ & 6 & $4.46 \pm 2.84$ \\
\hline & BioSampler & 3 & 3 & $136.61 \pm 103.59$ & & \\
\hline \multirow[t]{2}{*}{50} & AGI-30 & 3 & 0 & a & 6 & $1.24 \pm 0.66$ \\
\hline & BioSampler & 3 & 3 & $108.87 \pm 78.48$ & & \\
\hline \multirow[t]{2}{*}{70} & AGI-30 & 3 & 0 & a & 6 & $0.67 \pm 1.03$ \\
\hline & BioSampler & 3 & 1 & 0.00 & & \\
\hline \multirow[t]{2}{*}{90} & AGI-30 & 3 & 0 & $\mathrm{a}$ & 6 & $0.09 \pm 0.23$ \\
\hline & BioSampler & 3 & 1 & 0.00 & & \\
\hline
\end{tabular}

AGI, All-glass impinger

${ }^{a} R_{a}$ cannot be calculated because no virus was recovered from the sampler in any of the three tests

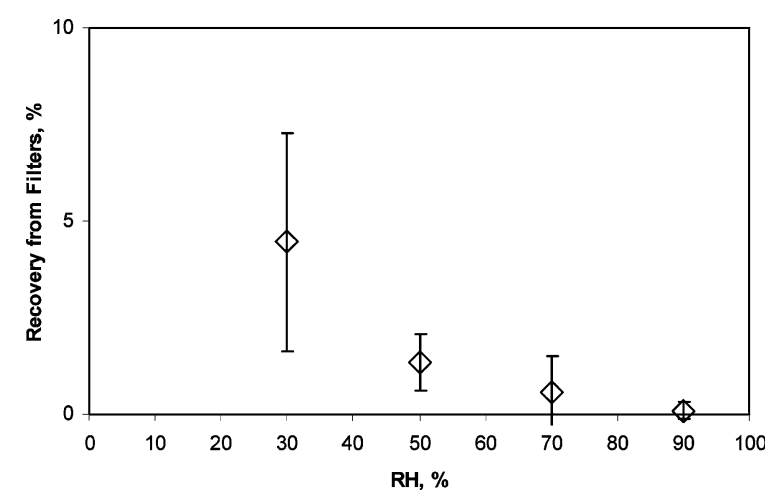

Fig. 3 Virus recovery from filters relative to nebulizer titers, $\mathrm{R}_{\mathrm{n}}$ from Eq. 4, as a function of relative humidity $(R H)$. Error bars represent \pm 1 SD from the mean for each condition

and the size distribution of the TGEV-containing particles being sampled is not known.

Figure 3 shows the results for virus recovery according to Eq. 4 as a function of RH. Overall recovery was less than $10 \%$. Potential reasons for recoveries less than $100 \%$ include (1) inactivation during nebulization, (2) inactivation during transport through the air, (3) inactivation during collection and retention on the test filter, and (4) penetration through the test filter. Because nebulization losses were shown to be minimal and the filters tested in this study were fairly efficient, most losses are probably due to inactivation during transport or during collection and/or retention on the test filter. The results in
Table 2 and Fig. 3 suggest that Eq. 4 is a more useful expression for evaluating TGEV recovery from filters than Eq. 3.

Our findings indicate that the survivability of TGEV decreased substantially in the short time between aerosolization and sampling. In addition, the higher recovery of TGEV at 30\% RH suggests that this virus may survive longer in an airborne state and after sampling or collection at low RH than at high RH. Akers (1969) has proposed that humiditydependent inactivation of aerosolized virus occurs immediately after they are sprayed and, once established, does not drastically changed with the aging of the aerosol. It is generally believed that lipidcontaining viruses, including TGEV, survive better at low levels of RH and that the high $\mathrm{RH}$ levels are more conducive to the airborne survival of lipid-free viruses (Sattar and Ijaz 1987).

\subsection{Comparisons to previous studies}

Many airborne viruses are affected greatly by the RH of the air. In this study, TGEV exhibited a better survival at low RH than at high humidity. Although the reasons for this behavior are uncertain, they may be related to TGEV's structure. In general, influenza virus survives best at low RH and low temperature (Loosli et al. 1943; Hemmes et al. 1962). Reoviruses show the least airborne viability near $50 \% \mathrm{RH}$ (Adams et al. 1982), while bacteriophage MS2 
aerosolized from $0.1 \mathrm{M} \mathrm{NaCl}$ was found to have the least relative recovery near $70 \% \mathrm{RH}$ (Trouwborst and De Jong 1973). Unlike coronaviruses such as TGEV and influenza viruses, neither reoviruses nor MS2 have an envelope. Our results, combined with those just mentioned, suggest that enveloped viruses may be equipped to survive more effectively at low $\mathrm{RH}$ than at high $\mathrm{RH}$, whereas non-enveloped viruses may behave differently.

Trouwborst and De Jong (1973) suggested that the inactivation of airborne virus is related to the airwater interface and that this may be an important mechanism for lipid-containing viruses like TGEV. Many biological materials are hygroscopic and demonstrate hysteresis in their water sorption isotherms. Following wet dissemination, the rate of desiccation depends on the prevailing $\mathrm{RH}$. The most portable target molecules of RH stress are outer membrane phospholipids and proteins (Cox 1989). This mechanism may partly explain the sensitivity of TGEV to relative humidity.

\section{Conclusions}

TGEV was nebulized, then sampled using AGI-30 impingers and BioSamplers, and finally collected on an HVAC test filter to measure the effects of nebulization stress and the recovery of viable virus from the filter. Titration of TGEV in an aqueous suspension before and after the suspension was nebulized indicated that the act of nebulization did not inactivate the virus. Not surprisingly, our results indicate that neither the type of nebulizer, the pressure of the air supplied to the nebulizer, nor the duration of nebulization affected the viability of TGEV significantly. Virus recoveries calculated based on the amount of the TGEV-containing suspension nebulized $\left(\mathrm{R}_{\mathrm{n}}\right)$ showed a dependence on $\mathrm{RH}$, with higher virus recovery at $30 \% \mathrm{RH}$ than at higher humidities. The reason for this behavior is uncertain, but the results are consistent with those of previous investigations and suggest that enveloped viruses have a different relationship between virus recovery and humidity than non-enveloped viruses. Aerosolization efficiencies were also higher at lower RH, and BioSamplers collected airborne TGEV viruses at a significantly higher efficiency than AGI-30 samplers at 30 and $50 \%$ RH. All of the results reported here are specific to TGEV, and the extent to which these results with TGEV apply to other coronaviruses like the SARS virus has not yet been tested. However, TGEV's behavior is likely to be comparable to that of other coronaviruses due to structural similarities. Other viruses, particularly those from other genera, may behave differently.

Acknowledgements This study was supported in part by a grant from the Pilot Project Research Training Program of the NIOSH-sponsored Midwest Center for Occupational Health and Safety at the University of Minnesota, by Minnesota Medical Foundation award 3660-9227-06, and by a Nontenured Faculty Grant from 3M Company.

\section{References}

Adams, D. J., Spendlove, J. C., Spendlove, R. S., \& Barnett, B. B. (1982). Aerosol stability of infectious and potentially infectious reovirus particles. Applied and Environmental Microbiology, 44, 903-908.

Agranovski, I. E., Safatov, A. S., Pyankov, O. V., Sergeev, A. N., Agafonov, A. P., Ignatiev, G. M., Ryabchikova, E. I., Borodulin, A. I., Sergeev, A. A., Doer, H. W., Rabenau, H. F., \& Agranovski, V. (2004). Monitoring of viable airborne SARS virus in ambient air. Atmospheric Environment, 38, 3879-3884.

Agranovski, I. E., Safatov, A. S., Pyankov, O. V., Sergeev, A. A., Sergeev, A. N., \& Grinshpun, S. A. (2005). Long-term sampling of viable airborne viruses. Aerosol Science \& Technology, 39, 912-918.

Akers, T. G. (1969). Survival of airborne virus, phage, and other minute microbes. In R. L. Dimmick \& A. B. Akers (Eds.), Introduction to experimental aerobiology (pp. 296-339). New York: Wiley-Interscience.

ASHRAE (2000). ASHRAE standard 52.2-1999: Method of testing general ventilation air-cleaning devices for removal efficiency by particle size. Atlanta: American Society of Heating, Refrigerating, and Air-Conditioning Engineers.

Brockmann, J. E. (2001). Sampling and transport of aerosols. In P. A. Baron \& K. Willeke (Eds.), Aerosol measurement (pp. 143-195). New York: Wiley-Interscience.

Buttner, M. P., \& Stetzenbach, L. D. (1991). Evaluation of four aerobiological sampling methods for the retrieval of aerosolized Pseudomonas syringae. Applied and Environmental Microbiology, 57, 1268-1270.

Buttner, M. P., Willeke, K., \& Grinshpun, S. A. (2002). Sampling and analysis of airborne microorganisms. In C. J. Hurst (Ed.), Manual of environmental microbiology (pp. 814-826). Washington, DC: American Society for Microbiology Press.

Cox, C. S. (1989). Airborne bacteria and viruses. Science Progress, 73, 469-499.

Cox, C. S., Hood, A. M., \& Baxter, J. (1973). Method for comparing concentrations of the open-air factor. Applied Microbiology, 26, 640-642. 
Donaldson, A. I. (1978). Factors influencing the dispersal, survival and deposition of airborne pathogens of farm animals. The Veterinary Bulletin, 48, 83-89.

Farnsworth, J. E., Goyal, S. M., Kim, S. W., Kuehn, T. H., Raynor, P. C., Ramakrishnan, M. A., Anantharaman, S., \& Tang, W. (2006). Development of a method for bacteria and virus recovery from heating, ventilation, and air conditioning (HVAC) filters. Journal of Environmental Monitoring, 8, 1006-1013.

Fauquet, C. M., Mayo, M. A., Maniloff, J., Desselberger, U., \& Ball, L. A. (2005). Virus taxonomy, Eighth report of the International Committee on Taxonomy of Viruses. London: Academic Press.

Foarde, K. K., Hanley, J. T., \& Ensor, D. S. (1999). Development of a method for measuring single-pass bioaerosol removal efficiencies of a room air cleaner. Aerosol Science \& Technology, 30, 223-234.

Gerone, P. J., Couch, R. B., Keefer, G. V., Douglas, R. G., Derrenbacher, E. B., \& Knight, V. (1966). Assessment of experimental and natural viral aerosols. Bacteriological Reviews, 30, 576-588.

Hemmes, J. H., Winkler, K. C., \& Kool, S. M. (1962). Virus survival as a seasonal factor in influenza and poliomyelitis. Antonie van Leeuwenhoek, 28, 221-233.

Hitchcock, P. J., Mair, M., Inglesby, T. V., Gross, J., Henderson, D. A., O'Toole, T., Ahern-Seronde, J., Bahnfleth, W. P., Brennan, T., Burroughs, H. E. B., Davidson, C., Delp, W., Ensor, D. S., Gomory, R., Olsiewski, P., Samet, J. M., Smith, W. M., Streifel, A. J., White, R. H., \& Woods, J. E. (2006). Improving performance of HVAC systems to reduce exposure to aerosolized infectious agents in buildings: Recommendations to reduce risks posed by biological attacks. Biosecurity and Bioterrorism: Biodefense Strategy, Practice, and Science, 4, 41-54.

Hogan, C. J., Kettleson, E. M., Lee, M. H., Ramaswami, B., Angenent, L. T., \& Biswas, P. (2005). Sampling methodologies and dosage assessment techniques for submicrometre and ultrafine virus aerosol particles. Journal of Applied Microbiology, 99, 1422-1434.

Ijaz, M. K., Karim, Y. G., Sattar, S. A., \& Johnson-Lussenburg, C. M. (1987). Development of methods to study the survival of airborne viruses. Journal of Virological Methods, 18, 87-106.

Karber, G. (1931). 50\% end-point calculation. Archiv for Experimentelle Pathologie und Pharmakologie, 162, 480-483.

Lee, K. W., \& Liu, B. Y. H. (1982). Theoretical study of aerosol filtration by fibrous filters. Aerosol Science \& Technology, 1, 147-161.

Lin, X., Reponen, T. A., Willeke, K., Grinshpun, S. A., Foarde, K. K., \& Ensor, D. S. (1999). Long-term sampling of airborne bacteria and fungi into a non-evaporating liquid. Atmospheric Environment, 33, 4291-4298.

Lin, X., Reponen, T., Willeke, K., Wang, Z., Grinshpun, S. A., \& Trunov, M. (2000). Survival of airborne microorganisms during swirling aerosol collection. Aerosol Science \& Technology, 32, 184-196.

Loosli, C. G., Lemon, H. M., Robertson, O. H., \& Appel, E. (1943). Experimental airborne influenza infection. I. Influence of humidity on survival of virus in air. Proceedings of the Society for Experimental Biology and Medicine, 53, 205-206.
Marthi, B. (1994). Resuscitation of microbial bioaerosols. In B. Lighthart \& A. J. Mohr (Eds.), Atmospheric microbial aerosols (pp. 192-225). New York: Chapman \& Hall.

McCullough, N. V., Brosseau, L. M., Vesley, D., \& Vincent, J. H. (1998). Improved methods for generation, sampling, and recovery of biological aerosols in filter challenge tests. American Industrial Hygiene Association Journal, 59, 234-241.

Mitchell, J. P. (1995). Aerosol generation for instrument calibration. In C. S. Cox \& C. M. Wathes (Eds.), Bioaerosols handbook (pp. 101-175). Boca Raton: CRC Press.

Musher, D. M. (2003). How contagious are common respiratory tract infections? New England Journal of Medicine, $348,1256-1266$.

Nicas, M., Nazaroff, W. W., \& Hubbard A. (2005). Toward understanding the risk of secondary airborne infection: Emission of respirable pathogens. Journal of Occupational and Environmental Hygiene, 2, 143-154.

Otten, J. A., \& Burge, H. A. (1999). Viruses. In J. Macher (Ed.), Bioaerosols: Assessment and control (pp. 1-6). Cincinnati: American Conference of Governmental Industrial Hygienists.

Reponen, T., Willeke, K., Grinshpun, S., \& Nevalainen, A. (2001). Biological particle sampling. In P. A. Baron \& K. Willeke (Eds.), Aerosol measurement (pp. 751-777). New York: Wiley-Interscience.

Research Triangle Institute (2004). Environmental technology verification: Test report of control of bioaerosols in HVAC systems. Research Triangle Park: Research Triangle Institute, Engineering and Technology Unit.

Riley, E. C., Murphy, G., \& Riley, R. L. (1978). Airborne spread of measles in a suburban elementary school. American Journal of Epidemiology, 107, 421-432.

Sattar, S. A., \& Ijaz, M. K. (1987). Spread of viral infections by aerosols. Critical Reviews in Environmental Control, 17, 89-131.

Sattar, S. A., \& Ijaz, M. K. (2002). Airborne viruses. In C. J. Hurst (Ed.), Manual of environmental microbiology (pp. 871-883). Washington D.C.: American Society for Microbiology Press.

Spendlove, J. C., \& Fannin, K. F. (1982). Methods of characterization of virus aerosols. In C. P. Gerba \& S. M. Goyal (Eds.), Methods in environmental virology (pp. 261-329). New York: Marcel Dekker.

Thiel, V., Ivanov, K. A., Putics, Á., Hertzig, T., Schelle, B., Bayer, S., Weissbrich, B., Snijder, E. J., Rabenau, H., Doerr, H. W., Gorbalenya, A. E., \& Ziebuhr J. (2003). Mechanisms and enzymes involved in SARS coronavirus genome expression. Journal of General Virology, 84, 2305-2315.

Trouwborst, T., \& De Jong, J. C. (1973). Interaction of some factors in the mechanism of inactivation of bacteriophage MS2 in aerosols. Applied Microbiology, 26, 252-257.

Tseng, C., \& Li, C. (2005). Collection efficiencies of aerosol samplers for virus-containing aerosols. Journal of Aerosol Science, 36, 593-607.

Willeke, K., Lin, X., \& Grinshpun, S. A. (1998). Improved aerosol collection by combined impaction and centrifugal motion. Aerosol Science \& Technology, 29, 439-456. 